\title{
THE ATTITUDES OF PARENTS AND AUDIOLOGISTS ON \\ THE IMPLEMENTATION OF DIAGNOSTIC PROCEDURES IN CHILDREN WITH HEARING IMPAIRMENT
}

\author{
Esad H. Mahmutović ${ }^{1}$ \\ Sanela Čajlaković Kurtalić
}

Original scientific paper

The Center for Education and Rehabilitation of hearing and speaking Tuzla, B\&H

Received: 12.01 .2016

UDC: $376.1-056.263-053.2$

Accepted: 20.03.2016

616.28-008.14-053.2

\begin{abstract}
The aim of this study was to examine the attitudes of audiologists and hearing parents severely impaired children on the application of different ways of carrying out the diagnostic procedures. It was assumed that the attitudes of audiologists and parents of children with impaired hearing on the current - the classical method of performing diagnostic procedures unfavorable and that they need to be modernized with new information and communication technologies. The sample consisted of 90 subjects, divided into two subsample (45 audiologists and 45 parents). To estimate the attitudes applied questionnaire, specifically designed and tested for this study. Measuring response to claims made according to the Likert scale. For the processing of survey data were used descriptive analysis, one-way ANOVA and canonical discriminative analysis. By analyzing the data showed that there were unfavorable attitudes towards implementation of diagnostic procedures in the traditional manner and the need for their modernization of information and communication technologies. Also, it was found that there is a statistically significant difference in the attitudes of audiologists and parents towards the implementation of diagnostic procedures. The reasons for these results, visible on the basis of the coefficient of canonical discriminant function, can be traced to an insufficient level of knowledge of parents, low self-criticism audiologists to performing tasks, possibly their lack of expertise, as well as other latent causes.
\end{abstract}

Keywords: diagnosis, audiologists, parents, diagnostic procedures, information and communication technology

\section{INTRODUCTION}

Hearing loss is considered to be the most prevalent congenital abnormality in newborns and is more than twice as prevalent as other conditions that are screened for at birth, such as sickle cell disease, hypothyroidism, phynilketonuria, and galactosaemia (Finitzo \& Crumley, 1999, according to Shemesh, 2013). Hearing plays a role in informing and knowledge of objective reality, in terms of sound arousal, but the changes caused by their impairment may cause negative consequences expressed to a greater and lesser extent, in certain areas of development. Early detection, diagnosis and intervention are critical for minimizing the potentially seriousconsequences of hearing loss in children (Cole \& Flexer 2007, according to Dornan, 2010).

\footnotetext{
${ }^{1}$ Correspondence to:

Esad H. Mahmutović, The Center for Education and Rehabilitation of hearing and speaking Tuzla, B\&H

Husinskih rudara 161 10, Tuzla, B\&H

Phone: +38761 290780

E-mail: esad25@yahoo.com
} 
There is no satisfactory results in the elimination of the consequences of hearing impairment without timely matter detection and adequate work of diagnostic procedures which could evaluate all levels of development areas, especially speech and language, and determine initial platform for eventual action necessary methods and procedures, based on scientific principles that take into account the specifics established in an individual. According to Bernthal and Bankson (2004), it is important to distinguish the diagnostic evaluation of development areas out of screening procedure, carried out in order to obtain preliminary information and determine the need for a comprehensive review.

Diagnostic procedures, as a prerequisite for adequate rehabilitation treatment, including evaluation of all development areas, which is in its programming necessary to know and meet (discover) a causal link this development.

If the assessment field is to move forward in meaningful ways, it is important to develop a general assessment framework that can be used with all deaf and hard of hearing children. This framework must have enough flexibility and rationality to fit the varying assessment and intervention needs of this heterogeneous population, including the necessary psychometric standards and guidelines for translating test data into meaningful intervention and/or programming strategies and approaches. Deaf and hard of hearing infants, toddlers, children, and adolescents have developmental assessment issues that are not so different from their hearing peers. However, when establishing an assessment framework, theoretical templates, and evaluation protocols, one must call to mind the general nature of expected normal development for one particular age range on one particular measure of developmental behavior, taking into consideration the potential effects of both internal (within the child) and external (in the child's environment) factors (Miller, 2006).

The many changes in the treatment of children with hearing loss have necessitated the need for objective, quantifiable evidence, as clinical practice needs to be efficacious, effective, accountable, viable, equitable and acceptable (Crombie \& Davies, 1996, acoording to Doran, 2010).

Research activities in the last thirty years or more causes very noticeable and frequent technological and technical changes. This results in the rapid social development in those areas where this knowledge is practically applied. According to Gillard, Bailey and Nolan (2008), technology is truly everywhere and its widespread adoption and application has changed the way each and every one of us lives and makes a living in modern society.

For deaf people it is extremely important to introduce the use of information and communications technology on all levels of education and rehabilitation. This increases their ability to learn and improves their understanding of learning materials, especially if the applications are designed specifically for their needs. Through daily exposure to a larger number of such materials, we can positively influence the literacy (reading and writing skills) of the deaf. With increased literacy, the deaf would be able to read literature, and subtitles, enabling them to receive information through written sources. Therefore, we can expect them to have a higher self-esteem, more easily integrate into society and have more opportunities for employment (Debevc \& Peljhan, 2004). Results of research on the use of programmable dynamic rehabilitation contents showed significant displacement to improve the linguistic competence and quality in the communication of the deaf and hard of hearing people with hearing world, a dynamic methodological approaches in speech and linguistic education of hearing impaired children, making it easier to learn all the elements of speech and languages, primarily phonology and morphology, and semantics, syntax and grammar of the language of the hearing community (Hasanbegović, 2006). Technology in the education of $\mathrm{D} / \mathrm{HH}$ children holds the potential to prepare them to be successful in the future. Tied to the use of technology for this purpose are the preparation of new teachers and the support of existing teachers with an understanding of the complexities that they face in their classrooms. As evidenced in this chapter, educators with experience in the use of technology can share information with their colleagues (Miller, 2006).

Information technology in the rehabilitation of hearing impaired children has become a reality, both for professionals and for those people. Its application in the diagnosis, particularly the assessment of the status of the hearing and speech-language development, through the development of new ways of conducting diagnostic procedures, in compliance with realistic technological capabilities, can significantly improve the overall educational and rehabilitation process.

The aim of this study was to examine the attitudes of audiologists and hearing parents severely impaired children on the application of different ways of carrying out the diagnostic procedures. It was assumed that the attitudes of audiologists and parents of children with impaired hearing on the current - the classical method of performing diagnostic procedures unfavorable and that they need to be modernized with new information and communication technologies. 


\section{METHODS}

\section{The sample of an examinee}

The sample consisted of 90 subjects, divided into two subsamples. The first subsample consisted of 45 audiologists employed in institutions for education, training and rehabilitation of children with impaired hearing, more than two years. The second subsample consisted of 45 parents of deaf and hard of hearing children.

\section{Measuring instrument}

To estimate the attitudes of audiologists and hearing parents severely impaired children on the application of different ways of carrying out the diagnostic procedures applied questionnaire, specifically designed and tested for this study.

The questionnaire consisted of the following 15 statements which questioned the quality of diagnostic procedures, or in other word, the ways of their implementation:

1. Childs family, through counseling, is well-informed about the state of hearing the injured child and the role of the family in its development process.

2. Diagnostic procedures should not be based on a bilingual approach.

3. Often when preparing long waits in the waiting room or by ordering the execution of diagnostics procedures.

4. Counseling of parents of children with impaired hearing, by audiologists, how to support the child in the family is carried out properly and continuously.

5. Adequate diagnosis of children/people with hearing impairment occurs due to: sufficient expertise of the examiner, sufficient language competence, adequate tools, custom methods and ways of carrying out the assessment, having an objection to the adequacy of diagnostic procedures.

6. Diagnostic procedures should not be modernized by computer technology (make diagnostic software).

7. Diagnostic procedures are exhausting for the child/person.

8. Adequate diagnosis of children/people with impaired hearing takes place in the evalua- tion: hearing status, speaking status, linguistic status, psychological status, forecasts of development.

9. The results of diagnostic procedures should not have IT mobility and availability, via removable media (CD, stick, etc.) and the Internet.

10.The results of diagnostic procedures reflect the developmental level of the child/hearing impaired.

11.Diagnostic procedures are not adapted to the abilities (hearing and visual), children/people with hearing impairments.

12. The results of diagnostic procedures provide fast and clear insight into the individual development areas (hearing, speech and language, psychological...) condition of the child / hearing impaired.

13. Diagnostic procedures are not adapted to communication competencies (sign language, reading from the face) child/hearing impaired.

14. The results of diagnostic procedures have enough easily accessible (located in the files, sorted differently).

15.Modes of performing diagnostic procedures do not allow for frequent and simple repetition of procedures for continuous monitoring of the child/hearing impaired.

Measuring response to claims made according to the Likert scale, consisting of 5 categories (strongly agree, mostly agree, I cannot decide, mostly disagree and strongly disagree). The person who completes the questionnaire, with each choice argument selects only one acceptable answer for her/him, except for variable 5 and 8 where there was an opportunity to choose more than one answer. Testing is completed through interviews, in directly contact of respondents.

\section{Methods of data processing}

To process the data, the software package SPSS for Windows has been used. Within the descriptive analysis, calculate basic statistical indicators (minimum and maximum, mean, standard deviation, skewness and kurtosis). To determine the structural differences in the attitudes of diagnostic procedures, between the two subsamples of respondents (audiologists and parents), applied the one-way ANOVA and canonical discriminant analysis. 


\section{RESULTS AND DISCUSSION}

Descriptive statistical indicators of the results of research

Table 1 shows the descriptive statistical indicators of responses to claims in the assessment of diagnostic procedures. Within the parameters of the two subsamples of respondents there are significant deviations respondents on certain claims, and to certain assertions, there are differences between subsamples, which are specifically ex- pressed in the statements: $5,6,7,8,12,13,15$. These are claims which the activities directly related to the knowledge of diagnostic procedures and ways of their implementation, which requires a certain level of knowledge of respondents. Because on the one hand an audiologists, and on the other side of the parents, it can be concluded that the expertise influenced the differences in attitudes between the two subsamples of respondents.

The differences in the overall responses of all respondents, almost all claims, indicate the need for calculating the statistical significance of differences.

Table 1. Descriptive statistical indicators

\begin{tabular}{|c|c|c|c|c|c|c|c|}
\hline Claims & Subsamples & Min & Max & $\mathbf{M}$ & SD & $\overline{S_{k}}$ & $\overline{K_{u}}$ \\
\hline \multirow[t]{2}{*}{1.} & $\mathrm{P}$ & 1 & 5 & 2,93 & 1,286 & ,331 & $-1,209$ \\
\hline & A & 1 & 4 & 2,98 & 1,076 &,- 298 & $-1,557$ \\
\hline \multirow[t]{2}{*}{2.} & $\mathrm{P}$ & 1 & 5 & 2,27 & 1,629 & ,867 &,- 918 \\
\hline & A & 1 & 5 & 2,24 & 1,151 &, 524 &,- 797 \\
\hline \multirow[t]{2}{*}{3.} & $\mathrm{P}$ & 1 & 5 & 4,29 & 1,342 & $-1,680$ & 1,316 \\
\hline & A & 1 & 5 & 3,96 & 1,086 & $-1,022$ & 257 \\
\hline \multirow[t]{2}{*}{4.} & $\mathrm{P}$ & 1 & 5 & 3,64 & 1,368 &,- 485 & $-1,350$ \\
\hline & A & 1 & 5 & 3,60 & 1,156 &,- 902 &,- 084 \\
\hline \multirow[t]{2}{*}{5.} & $\mathrm{P}$ & 1 & 6 & 3,82 & 1,957 &,- 539 & $-1,439$ \\
\hline & A & 1 & 6 & 5,04 & 1,745 & $-1,576$ & 842 \\
\hline \multirow[t]{2}{*}{6.} & $\mathrm{P}$ & 1 & 5 & 1,13 &, 625 & 5,743 & 35,085 \\
\hline & A & 1 & 4 & 1,44 &, 659 & 1,709 & 3,830 \\
\hline \multirow[t]{2}{*}{7.} & $\mathrm{P}$ & 1 & 5 & 4,18 & 1,353 & $-1,490$ & ,769 \\
\hline & A & 1 & 5 & 3,62 & ,960 &,- 768 & ,219 \\
\hline \multirow[t]{2}{*}{8.} & $\mathrm{P}$ & 4 & 6 & 5,36 & ,679 &,- 583 &,- 672 \\
\hline & A & 2 & 6 & 5,69 &, 874 & $-3,601$ & 13,360 \\
\hline \multirow[t]{2}{*}{9.} & $\mathrm{P}$ & 1 & 5 & 1,69 & 1,221 & 1,653 & 1,384 \\
\hline & A & 1 & 4 & 1,93 & ,889 & ,743 &,- 054 \\
\hline \multirow[t]{2}{*}{10.} & $\mathrm{P}$ & 1 & 5 & 2,91 & 1,379 &,- 215 & $-1,402$ \\
\hline & A & 1 & 5 & 3,16 & 1,086 & 011 &,- 801 \\
\hline \multirow[t]{2}{*}{11.} & $\mathrm{P}$ & 1 & 5 & 3,47 & 1,531 &,- 649 & $-1,156$ \\
\hline & A & 1 & 5 & 3,33 & 1,168 &,- 339 &,- 769 \\
\hline \multirow[t]{2}{*}{12.} & $\mathrm{P}$ & 1 & 4 & 2,42 & 1,033 & 606 &,- 934 \\
\hline & A & 1 & 5 & 3,29 & 1,290 &,- 571 &,- 926 \\
\hline \multirow[t]{2}{*}{13.} & $\mathrm{P}$ & 1 & 5 & 3,82 & 1,466 & $-1,082$ &,- 306 \\
\hline & A & 1 & 5 & 3,31 & 1,104 &,- 131 & $-1,119$ \\
\hline \multirow[t]{2}{*}{14.} & $\mathrm{P}$ & 1 & 5 & 2,42 & 1,158 & ,842 & ,173 \\
\hline & A & 1 & 5 & 2,64 & 1,417 & ,420 & $-1,110$ \\
\hline \multirow[t]{2}{*}{15.} & $\mathrm{P}$ & 3 & 5 & 4,58 &, 583 & $-1,035$ & ,146 \\
\hline & A & 2 & 5 & 3,24 &, 908 &, 054 &,- 915 \\
\hline
\end{tabular}

\section{The results of One-Way ANOVA}

Table 2 shows the results of one-way ANOVA results. Based on the results F - test, it was found that in six of the fifteen claims present a statistically significant difference (significance level 0.05 ). In relation to the size of the coefficient $\mathrm{F}$ for all claims, the dimension of "Methods of execution of diagnostic procedures often do not allow for simple retrieval procedures for continuous monitoring." (claim $15-\mathrm{F}=68,631$ ) recorded the most pronounced differences between groups of respondents. 
Table 2. ANOVA

\begin{tabular}{|c|c|c|c|c|c|}
\hline Claims & Wilks' Lambda & $\mathbf{F}$ & df1 & df2 & Sig. \\
\hline 1. & 1,000 &, 032 & 1 & 88 &, 859 \\
\hline 2. & 1,000 & ,006 & 1 & 88 & ,941 \\
\hline 3. & ,981 & 1,677 & 1 & 88 & ,199 \\
\hline 4. & 1,000 &, 028 & 1 & 88 & ,868 \\
\hline 5. & ,900 & 9,778 & 1 & 88 &, 002 \\
\hline 6. & ,943 & 5,278 & 1 & 88 &, 024 \\
\hline 7. & ,946 & 5,044 & 1 & 88 & ,027 \\
\hline 8. & ,956 & 4,077 & 1 & 88 & ,047 \\
\hline 9. & ,987 & 1,178 & 1 & 88 & ,281 \\
\hline 10. & ,990 & 873 & 1 & 88 &, 353 \\
\hline 11. & ,998 & ,216 & 1 & 88 & ,634 \\
\hline 12. & ,877 & 12,370 & 1 & 88 & ,001 \\
\hline 13. & ,962 & 3,490 & 1 & 88 &, 065 \\
\hline 14. & ,993 & ,664 & 1 & 88 & ,417 \\
\hline 15. &, 562 & 68,631 & 1 & 88 &, 000 \\
\hline
\end{tabular}

\section{The results of Canonical Discriminant Analysis}

With the application of canonical discriminant analysis, determining the actual structure of the difference in the attitudes of diagnostic procedures between the two groups enabled the exploration of the latent content dimension based on knowledge of the claims, respectively, of the linear function that separates the maximum group. On the results of the responses to 15 statements calculated multivariate statistical significance of the difference, and then determined the structure of the discriminant function, based on the size of the correlation of certain variables with discriminant function.

Since the discriminant analysis was applied to two groups, one common separate discriminant func- tion (Table 3). Based on the value of Wilks' Lambda (,437), Barttlet Chi-square - $\chi 2=66,699$, df $=15$, $\mathrm{p}<, 00$, one can see that the maximum discriminant function separates a group of parents, groups of audiologists, in another word, respond to the allegations in the survey questionnaire affect significantly differentiate these two groups in attitudes towards diagnostic procedures.

Eigenvalue of discriminant function, which is $\lambda=$ 1,290 , indicating the importance dimension for the classification of the dependent variable, while the value of canonical correlation of $\mathrm{R}=, 751$, indicating a strong association between the discriminant function with two groups of respondents, or about high discriminatory power obtained functions.

Table 3. Eigenvalue, Canonical Correlation Coefficients, Wilks' Lambda and Chi-square

\begin{tabular}{cccccccc}
\hline \multirow{2}{*}{ Function } & Eigenvalue & \% of Variance & $\begin{array}{c}\text { Canonical } \\
\text { Correlation }\end{array}$ & $\begin{array}{c}\text { Wilks' } \\
\text { Lambda }\end{array}$ & Chi-square & df & Sig. \\
\hline 1 & 1,290 (a) & 100,0 &, 751 &, 437 & 66,699 & 15 &, 00 \\
\hline
\end{tabular}


Compared to the group centroids, it is also important that the discriminant function separates the parent

group $(-1,123)$, the group of audiologists $(1,123)$ (TaTable 4. Functions at Group Centroids ble 4).

\begin{tabular}{cc}
\hline Subsamples & Function1 \\
\hline Parents & 1,123 \\
Audiologists & $-1,123$ \\
\hline
\end{tabular}

As the results show a high overall response to discrimination claims, the further procedure is tested by the claims individually most important discriminating group.

Table 5 presents the values of structural (*Function1) and standardized coefficients (** Function 1$)$ on which to construct the discriminant function. Based on the structural coefficients, in other word, the coefficients of correlation with the discriminant function, the value of the first five variables $(15,12,5,6$ and 7$)$, in which $F$ and the coefficient determined based on the statistical significance of differences, show significant loads in the matrix structure of the discriminant function four following claims somewhat, and the other six have the lowest discriminatory power in discrimination group.

Responds which contributing most to the difference subsamples according to diagnostic procedures and their use are obtained from claims:

15. Modes of performing diagnostic procedures do not allow for frequent and simple repetition of procedures for continuous monitoring of the child/hearing impaired.

12. The results of diagnostic procedures provide fast and clear insight into the individual development areas (hearing, speech and language, psychological...) condition of the child/hearing impaired.
5. Adequate diagnosis of children/people with hearing impairment occurs due to: sufficient expertise of the examiner, sufficient language competence, adequate tools, custom methods and ways of carrying out the assessment, having an objection to the adequacy of diagnostic procedures.

6. Diagnostic procedures should not be modernized by computer technology (make diagnostic software).

7. Diagnostic procedures are exhausting for the child/ person.

These claims are most directly related to diagnostic procedures and the manner of their implementation, as noted in the descriptive analysis, and the same can be concluded that in response to any need some knowledge, however, is inadequate knowledge parents can be regarded as one of the causes of differences in attitudes. Also, the causes should be sought and the low level of self-criticism audiologists to performing tasks that mitigate the answers to the above statements, but possibly also their lack of expertise. Considering that statistically significant differences between subsamples response, it is necessary to conduct new research to discover other, this causes a latent significance.

Table 5. Structure matrix and Standardized Canonical Discriminant Function Coefficients

\begin{tabular}{ccc}
\hline Claims & ${ }^{*}$ Function1 & ${ }^{* *}$ Function1 \\
\hline $\mathbf{1 5 .}$ & $\mathbf{- , 7 7 8}$ & $\mathbf{- , 9 3 9}$ \\
$\mathbf{1 2 .}$ & $\mathbf{3 3 0}$ & $\mathbf{4 8 8}$ \\
$\mathbf{5 .}$ & $\mathbf{2 9 3}$ & $\mathbf{4 7 8}$ \\
$\mathbf{6 .}$ & $\mathbf{, 2 1 6}$ & $\mathbf{0 9 8}$ \\
$\mathbf{7 .}$ & $\mathbf{- , 2 1 1}$ & $\mathbf{1 4 2}$ \\
8. &, 190 &, 064 \\
13. &,- 175 &, 070 \\
3. &,- 122 &,- 001 \\
9. &, 102 &, 125 \\
10. &, 088 &,- 212 \\
14. &, 076 &,- 214 \\
11. &,- 044 &, 177 \\
1. &, 017 &, 178 \\
4. &,- 016 &,- 203 \\
2. &,- 007 &,- 164 \\
\hline
\end{tabular}


In the generally accepted model of the diagnosis and rehabilitation in small deaf children, the main concern of various specialists is focused on the development of speech and hearing abilities. In our approach, we propose another perspective, in which the deaf child is not seen as an object of the speech education and where the specialists concentrate on the child as a whole--with his various emotional needs and psychical traits. According to that way of seeing the deaf child, we organized the diagnostic-rehabilitation courses for small deaf children and their parents (9 children aged 1.8-5 years). We found these courses as a method opening new perspectives in the process of the diagnosis and rehabilitation in the small deaf children (Zalewska et al., 1990). The results suggest that success is achieved when early identification is paired with early interventions that actively involve families (Moeller, 2000).

Parental and family values, beliefs, culture, expectations, and previous life experiences, as well as current features of social ecology, will influence what is determined as effective, significant, and valued in relationships with service providers and in response to specific interventions (Aytch et al., 1999; Dyke, Buttigieg, Blackmore, \& Ghose, 2006; King et al., 1996; Young et al., 2006). According to Haug (2011), many paper-and-pencil tests have been converted to computer-based or web-delivered tests. Test content may not change, but two of the main advantages are that scores are stored automatically and that subjects can receive a report of their performance immediately after completing the test. Choi, Kim, and Boo (2003) compared the same language test delivered in paperand-pencil and computer-based versions and found that scores from both formats were comparable.

Unfavorable views of both subsamples in this study according to the classical method of performing diagnostic procedures, in almost all the claims, which were expected and proven, scientifically-based contribution to highlight the need to improve the quality of diagnostics in rehabilitation of hearing and speech, in particular, through the application of new, modern information technology.

\section{CONCLUSION}

Based on testing of audiologists and parents of children with hearing impairments, there are generally unfavorable attitudes towards implementation of diagnostic procedures in the traditional manner with a strong need for the modernization of new, information-communication technologies. Also, it was found that there is a statistically significant difference in the attitudes of audiologists and parents towards the implementation of diagnostic procedures. The reasons for these results, visible on the basis of the coefficient of canonical discriminant function, can be traced to an insufficient level of knowledge of parents, low self-criticism audiologists to performing tasks, possibly their lack of expertise, as well as other latent causes.

\section{REFERENCES}

Bernthal, J. E., \& Bankson, N. W. (2004). Articulation and phonological disorders (5. edition). Boston, MA: Pearson Education, Inc.

Debevc, M., \& Peljhan, Z. (2004). The role of video technology in on-linelectures for the deaf. Disability and Rehabilitation, 26 (17), 1048-1059. doi: 10.1080/09638280410001702441

Dornan A. D. (2010). Outcomes for Young Children with Hearing Loss in an Auditory-Verbal Therapy Program. A thesis submitted for the degree of Doctor of Philosophy at the University of Queensland in November 2010, School of Health and Rehabilitation Sciences. Retrived from: http://espace.library.uq.edu.au/view/ UQ:237839

Gillard, S. Bailey, D. \& Nolan, E. (2008). Ten Reasons for IT Educators to be Early Adopters of IT Innovations. Journal of Information Technology Education, 7, 21-33. Retrived from: http://jite.org/documents/Vol7/ JITEv7p021-033Gillard257.pdf

Hasanbegović, H. (2006). Rehabilitation programs in the language development of deaf, doctoral dissertation. [Rehabilitacijski programi u jezičnom razvoju gluhih, doktorska disertacija] B\&H, Tuzla: Univerzity of Tuzla

Haug, T. (2011). Adaptation and evaluation of a German Sign Language Test - A computer-based receptive skills test for deaf children ages 4-8 years old. Hamburg, Germany: Hamburg University Press. Retrived from: http:// hup.sub.uni-hamburg.de/purl/HamburgUP_Haug 
Miller, M. (2006). Individual Assessment and Educational Planning: Deaf and Hard of Hearing Students Viewed Through Meaningful Contexts. U knjizi Moores, F. D. i Martin S. D. (Editori). Deaf Learners. Developments in Curriculum and Instruction (161-177). Washington, D.C. 20002: Gallaudet University Press

Moeller, P. M. (2000). Early Intervention and Language Development in Children Who Are Deaf and Hard of Hearing. Pediatrics. 106 (e43), 1-9. doi: 10.1542/ peds.106.3.e43 Shemesh, R. (2013). Hearing Impairment: Definitions, Assessment and Management. U: Stone, H. J. \& Blouin, M. (Urednici). International Encyclopedia of Rehabilitation. Retrived from: http:// cirrie.buffalo.edu/encyclopedia/en/article/272
Young, A., Gascon-Ramos, M., Campbell, M. \& Bamford, J. (2009). The Design and Validation of a Parent-Report Questionnaire for Assessing the Characteristics and Quality of Early Intervention Over Time. J. Deaf Stud. Deaf Educ, 14 (4), 422-435. doi: 10.1093/deafed/ enp016

Zalewska, M., Wojciechowska, E., Schier, K., SobieszczańskaRadoszewska, L., Siedlecka, H. \& Bralczyk T. (1990). Searching new diagnostic and rehabilitation techniques in small deaf children (abstract). Retrived from: http://www.ncbi.nlm.nih.gov/pubmed/2152417 